\title{
Executive profile of adults with intellectual disability and psychomotor intervention' effects on executive functioning
}

\author{
Ana R Rodrigues ${ }^{*}$, Sofia Santos ${ }^{2 *}$, Ana Rodrigues ${ }^{2}$, Mónica Estevens ${ }^{3}$ and Elisabete Sousa ${ }^{3}$ \\ ${ }^{1}$ Faculdade de Motricidade Humana, Universidade de Lisboa, Portugal \\ ${ }^{2}$ Faculdade de Motricidade Humana, UIDEF - Instituto de Educação, Universidade de Lisboa, Portugal \\ ${ }^{3}$ Transition Center for the Adult and Active Life of the Cooperative of Education and Rehabilitation of Citizens with Disabilities in Lisbon, Portugal
}

\begin{abstract}
Executive functioning analysis has gaining a growing interest in adaptive and functional behaviour. Its laboratorial evaluation, based exclusively in structured test, is not enough to discriminate the real everyday executive functioning abilities in daily routines, being needed measures with ecological validity. Based both on lack of evidences about executive functioning of adults with intellectual disability (ID) and the need to validate best psychomotor practices, this article aims to describe the executive functioning of 18 adults between 22 and 57 years $(40.33 \pm 8)$, and to analyse the potential contribute that a psychomotor intervention executive functioning-centred can have in daily routines' promotion. The short version of Barkley Deficits in Executive Functioning Scale was applied in its self-report and report-of-others form. Results pointed out executive functioning limitations specifically in impulsivity, self-organization and self-emotional regulation. Staff tends to report more limitations than participants with ID themselves. Psychomotor intervention seems to have positive outcomes in all domains except self-motivation. The recommendation is for further investigation in executive functioning of adults with ID aiming better practices.
\end{abstract}

\section{Introduction}

Persons with Intellectual Disability (ID) are characterized by presenting significant intellectual and adaptive limitations expressed in conceptual, social and practical domains [1]. Although some evidences of limitations in the Executive Functions (EF) of persons with ID, there are still scarce research on area [2]. Executive functioning has gained increasing interest in human development [3], since EF are seen as the "Operations Center" [4] with impact in daily life - such as in learning processes [5], employment [6], community living [7], and quality of life [8].

Although the executive functioning conceptualization is still not consensual [9], EF encompasses a set of complex mental processes that impacts socio emotional adaptation [10]. There are three main interacting EF abilities $[3,11]$ : cognitive flexibility to change or alternate between tasks for decision making and action adequacy; working memory to allow update and monitor representations giving meaning to sequences of events occurring over time; and inhibitory control responsible for the behaviours regulation towards a goal or $[12,13]$. The EFs consist of top-down cognitive inputs, involving selection of information, its storage in the work memory for the decision-making and action adequacy [14].

EF allow the environment' adaptation, enabling to "stop to think before acting" and by offering a "working space" (i.e. working memory) which will affect the anticipation for a tailor-fit response [15], as well the inhibition of impulsive or automatic impaired responses [4]. The development of EFs assume a fundamental role at the adaptive level, specifically at monitoring behavioural change and planning future actions.

The environment' age and quality of inputs influence the efficiency of the neuronal network development, basis for the executive functioning [11]. The relationships between EF and intelligence (IQ) are reported
[16], despite low correlation values, and although some inconclusive results [17]. However, evidences suggest that poor executive functioning is a relevant component in (major) functional difficulties [18].

The executive functioning of the person with ID is characterized by: an attentional capacity of low quality and of reduced duration $[19,20]$, limitations in working memory, dysfunctional planning and problem solving skills [19], as well as in anticipation of the cause- effect system [1], difficulties in controlling impulsivity [21] and distractibility, with behavioural changes (e.g. apathy, aggression and limitations in perseverance) [22].

Performance in problem-solving tasks [23] and that require working memory [24], appears to be identical between adults with ID and their peers of the same mental age $[23,24]$ but lower with the same chronological age [25]. The motivation and persistence in causeeffect tasks in the first years of life in individuals with ID seems to be a predictor of executive function at more advanced ages [12].

Alloway [26] found significant differences in work memory level, verbal and visuo spatial domains between persons with and without ID. Danielsson, et al. [2] report difficulties in some executive areas of adults with ID, such as verbal fluency, access and retrieval of lexical items based on somatic/semantic roles and, consequently, the speed at which this process occurs; evocation of words by the work memory, namely in the codification of these. Adults with ID seem to present limitations in:

*Correspondence to: Ana R Rodrigues, Faculdade de Motricidade Humana, Universidade de Lisboa, Portugal, E-mail: sofiasantos@fmh.ulisboa.pt

Key words: ecological assessment, executive functions, intellectual and developmental disability, psychomotor therapy intervention

Received: June 01, 2019; Accepted: July 11, 2019; Published: July 16, 2019 
establishing abstract relationships between items, finding similarities between categories, dealing with unforeseen situations or cognitive (in)flexibility, which results from limitations in the organization of cognitive strategies, and limitations in behavioural self-regulation, highlighting the difficulties in inhibiting inappropriate responses which increase with the level of severity [27].

The assessment of the executive functioning is still mainly done in laboratorial settings and based on rigid tasks, with no apparent relation with daily activities [10]. However, it should include an ecological approach, for a better understanding and interpretation on the functional applications and on the matching process and behaviour [9]. Based on the still scarcity of evidence about executive functioning of adults with ID $[2,12,18]$, and by the need for validation of good psychomotor practices [28] this study has a two-fold goal: 1) describe the executive functioning of adults with ID through an ecological assessment of the impact on the daily life; and 2) the analysis of the possible contribution that a psychomotor intervention may have in the executive functioning.

\section{Methods}

\section{Participants}

The convenience sample consisted of a group of 18 adults between 22 and 57 years old $(40.33 \pm 8.0)$, diagnosed with ID, institutionalized and attending a centre of occupational activities (COA) of an institution in Lisbon. The inclusion criteria were the existence of a diagnosis of ID, all adults (over 18 years of age), with verbal and comprehension capacity to answer the questionnaire, and to attend the institution's COA. Participants, after selected, were randomly divided into two groups: with intervention $(\mathrm{n}=9$ ), between 33-57 years old, 6 males and 3 females, and without intervention $(n=9)$ between $22-44$ years old, 5 male and 4 females. Supports usually attended by participants were maintained and only the participants of the intervention group benefited from psychomotor intervention. All participants were medicated. Six female caregivers, between 23 and 57 years, responded the report-of-other version, of which 1 was a psychomotor therapist, 1 CAO monitor, 2 childhood educators, 1 occupational therapist, and 1 teaching assistant. Every respondent known clients for at least 2 years in a variety of contexts.

\section{Instruments}

All participants were evaluated by the reduced version of Barkley Deficits in Executive Functioning Scale [4] that aims to assess EF of adults between 18 and 81 years. It has two forms: self-report and report-of-others that should be administered as a clinical interview $[4,29]$. The scale has 20 items organized by 5 dimensions $[4,29]$ : selfmanagement to time assessed by procrastination (item1), forgetfulness (item2), planning (item 3), and time managements capacities (item4); self-organization/problem solving covering difficulties in the capacity for sequencing (item 6), information processing accuracy and speed (item 8), learning (item 5) and problem solving (item 7); self-restraint related to impulsiveness (item 10), foresight and hindsight (item 12), frustration tolerance (item 9) and ability to inhibit responses prior to considering their consequences (item 11); self-motivation which evaluates ability to work toward long-term goals or rewards (item13), put forth consistent effort (item 15), work without supervision (item 16), and exercise willpower (item 14); self-regulation of emotion, with items within the scope emotional control (item17), self-smoothing (item 19), tendency toward emotional excitement or overreaction (item 20 ), and ability to perceive events objectively (item 18).
The answer is categorized as "Never or rarely" (1 point), "sometimes" ( 2 points), "Often" ( 3 points) and "Very often" (4 points), being "1" the ideal answer. Each dimension score is obtained by summing the respective items and the final quotation involves the sum of the results of the dimensions [4]. The comparison of the self-report and report-ofothers versions allows the analysis of the disparity of the answers given $[4,29]$. The higher the result, more difficulties will be in this parameter: "normal", "marginal clinical significance", "borderline or somewhat deficient", "mildly deficient", "moderately deficient" or "Markedly deficient or severe" [4].

The self-report version was applied to 1249 adults, aged 18 and 96 years. Internal consistency $(.91>\alpha<.96)$ and temporal stability scores $(.62>\mathrm{r}<.80)$ indicated its reliability. The criterion $(p<.001)$ and construct validity, through Pearson's correlations $(.04>\mathrm{r}<.41$ and -.01 $>\mathrm{r}<-.31$ ), were significant and satisfactory [29]. The versions used in this article were translated by the author. The short form was chosen because it is short, brief and easy to apply.

\section{Procedure}

To carry out the study, all ethical requirements were fulfilled: authorization was asked, informed consents explaining all the research was given to potential participants. Confidentiality and anonymity were guarantee. After the collection of signed informed consent, initial evaluation was carried out, with the application of the scale in its double form (self-report and report-of-others) by the principal investigator, two times before intervention, establishing a baseline. These results allowed the establishment of general and specific objectives and the planning of a psychomotor intervention centred on executive functions. The same scale was applied after the end of the psychomotor program to analyse its effects and again one month after to analyse the potential retention effects (the retention assessment was performed only in the intervention group, due to the unavailability of a great number of caregivers and some absences of participants).

Psychomotor intervention, as one of the supports provided to adults with ID in institutions, is based on a holistic perspective of the person in constant relation with his/her environment. Its main goal is to promote adaptive and functional behaviours through movement and body experiences, aiming an immediate transfer to daily life of psychomotor competences [28]. In this context, a plan of psychomotor intervention was elaborated, with rigid structure sessions, organized in order to create pleasant routines, promoting motivation, and based on a sequential logic (spatial and temporal).

The planned 5-month psychomotor intervention, with weekly sessions of 45 minutes was implemented and focused on psychomotor and cognitive-executive competences. The characteristics needs and interests of each participant, even if in-group sessions were taken into account. Psychomotor goals were centred in the promotion of tonus, dynamic balance, body notion, space-time structuring, and gross motor skills. Cognitive-executive goals focused in working memory (adequate use of the information and promotion of selective attention), planning capacity, cognitive flexibility, receptive and expressive language (understanding of simple and complex instructions, quality of speech) and behaviour regulation. Every session had an initial moment of warm-up (5/10 min), followed by a set of activities (30/35 min) and a final reflection moment $(5 / 10 \mathrm{~min})$. Several principles were used as intervention guide: analysis, reflection and adjustment of events during the session play an active role in promoting self-regulation, and when there are obvious difficulties in the attention capacity; tasks gradual complexification was considered and transfer to daily life was also other 
main principle. Positive reinforcement and feedback, demonstration and simple instructions were some of the strategies used throughout all intervention, as well physical support when necessary.

\section{Results}

Firstly, was made a preliminary analysis of scale' psychometric qualities: content validity, reliability and finally, the construct validity through inter-domain correlation (Table 1) in both forms (self and otherreport) to assess the consistency between two groups of respondents.

Temporal stability scores (test-retest) range from moderate $(.40<$ $\mathrm{r}<.75)$ to strong $(>.75)$ in both versions (self and other-report), with weak correlations in the self-management of time and self-motivation domains $(<.30)$ in self-report form, which points to the need for greater attention to a more accessible language. Internal consistency also assumes excellent values $[30,31]$ in all domains in the report-ofothers $(\alpha>79)$, ranging from .22 (inadequate) in the self-motivating domain to .81 (excellent) in the total scale in the self-report form. The total score indicates the internal consistency on both forms. The initial results obtained by the participants are presented in table 2 .

Some differences were found between groups of respondents with self-report answers tending to less limitation. There is a tendency to postpone events, weak capacity to effectively plan actions/events and manage their activities, learning difficulties, limitations in sequencing elements, problem solving and inhibition of responses before considering their consequences. Further, it was identify a slower and less accurate information processing capacity, showing some intolerance to frustration, presence of impulsive behaviours and difficulty in selfregulating emotionally, not always being able to predict future events based on past events or to perceive some of them as a objectively way, working with poor effectiveness towards long-term goals.

The comparative study between the two groups (with and without intervention), was done using the Mann-Whitney test, in the three moments of evaluation (Table 3 ). There were significant differences in some domains, with a decrease in mean values after the psychomotor intervention, indicators of slight improvements, especially on the intervention group.

The Wilcoxon test was used to analyse the results between the different moments of the evaluation of each group, from the perspective of self and technicians reporting (Table 4), trying to examine the possible contribution of psychomotor intervention in the executive functioning, finding significant differences in some domains.

When analysed the comparison between the initial and final moments, it is possible to observe positive effects in self-management to time and self-restraint domains. In self-report only self-restraint domain presented significant differences. Report-of-others responses evidenced improvements in self-management to time, self-organization/ problem solving, self-restraint, and self-regulation of emotion domains, although without significant differences. Mean values obtained one month after the intervention tended to increase slightly in both groups.

\section{Discussion}

In Portugal, the evidence of executive and functional profile of people with ID is scarce, needing psychomotor practices validation. This paper aims to contribute to literature, describing the executive profile of adults with ID and analysing the contribution of a psychomotor intervention in executive functioning in daily tasks and adaptive behaviour [13,26].

Due to the lack of a Portuguese ecological instrument for evaluating executive functioning for adults, the scale was translated, then back translated and both versions were compared to clarify the semantic equivalence, linguistics and content. Next, three experts analysed the relevance, clarity, simplicity and ambiguity of the items, and the response options [32], for a better understanding of respondents, especially in self-report, considering the cognitive characteristics of the target population [33]. In this phase was maintained the same structure, trying to avoid ambiguous language. Small disagreements were solved by focus group, with a reformulation of some items.

Reliability was also examined. Temporal stability scores mostly indicated moderate to strong correlations, corroborating the original version, although the lower scores of our study [29]. The reduced number of our sample $(\mathrm{n}=18)$ compared to the original $(\mathrm{N}=1249)$, as well as the limited opportunity and experience that adults with ID enjoy in research participation, may explain the need for language simplification. Internal consistency seems to be acceptable or even excellent in the report-of-others version (> .79), although inferior and inadequate in the self-report version, especially in the selforganization domain. These results can be explained by the limitation in understanding information by persons with ID $[1,19,20]$, which may influence an inconsistent interpretation in the quotation criteria, and less recognition of their capabilities and limitations. In future it is suggested a special attention to these issues.

The weaker correlations, in self-report, were between domains self-management to time and self-motivation $(<.30)$, which can be explained by differences on competences and functional level of participants, by the discrepancy in their choices and motivations, and if they correspond or not to reality. Interestingly, the domain of selfmotivation, from the report-of-others perspective, showed the higher correlation scores, whose answers indicated greater limitations by participants with ID, corroborating the association of motivational difficulties in people with ID [34].

Despite the relevance of the individual perspective and given the cognitive characteristics of people with ID [33], the report-of-others version were applied [35] to assess the accuracy of self-report responses [36] and to measure in-depth individual performance. The correlation

Table 1. Pearson correlation coefficient (r) and internal consistency (Cronbach's alpha) results from the self-report (SR) perspective and the report-of-others (RO) responses

\begin{tabular}{|c|c|c|c|c|c|c|c|c|c|c|c|c|c|c|c|}
\hline & \multicolumn{2}{|c|}{ r test-retest } & \multicolumn{2}{|c|}{ Alpha Cronbach $(\alpha)$} & \multicolumn{3}{|c|}{ SR r } & \multicolumn{2}{|c|}{ RO r } & \multicolumn{6}{|c|}{ r (SR \& RO) } \\
\hline & SR & RO & SR & RO & SM & SO & $\mathrm{Sr}$ & SM & SRE & SM & SO & $\mathrm{Sr}$ & SM & SRE & \\
\hline SM & .29 & .71 & .54 & .92 & - & - & - & - & - & - & - & - & - & - & .51 \\
\hline SO & .44 & .72 & .22 & .86 & .42 & - & - & - & - & .24 & - & - & - & - & .48 \\
\hline SR & .52 & .50 & .63 & .79 & .55 & .16 & - & - & - & .02 & .29 & - & - & - & .70 \\
\hline SM & .22 & .89 & .57 & .85 & .55 & .32 & .32 & - & - & .87 & .53 & .21 & - & - & .38 \\
\hline SRM & .80 & .58 & .80 & .88 & .60 & .35 & .25 & .11 & - & .01 & .02 & .68 & .10 & - & .55 \\
\hline Total & .61 & .58 & .81 & .88 & .89 & .58 & .72 & .55 & .72 & .70 & .58 & .63 & .84 & .55 & .76 \\
\hline
\end{tabular}

SM: Self-management to time; SO: Self-organization/problem solving; Sr: Self-restraint; SM:Self-motivation; SRE: Self-regulation of emotion 
Table 2. Initial results obtained by the participants (P) in the self-report (SR) and other report (OR)

\begin{tabular}{|c|c|c|c|c|c|c|c|c|c|c|c|c|c|c|c|c|c|c|}
\hline Item & P1 & P2 & P3 & P4 & P5 & P6 & P7 & P8 & P9 & P10 & P 11 & P 12 & P 13 & P 14 & P 15 & P 16 & P 17 & P 18 \\
\hline 1OR & 1 & 2 & 4 & 2 & 2 & 3 & 1 & 2 & 1 & 2 & 2 & 4 & 2 & 3 & 2 & 1 & 4 & 2 \\
\hline $1 \mathrm{SR}$ & 1.5 & 2.5 & 2.5 & 1 & 1 & 3.5 & 1.5 & 1 & 1 & 2.5 & 1 & 1.5 & 1 & 2 & 1 & 2 & 1.5 & 1 \\
\hline $2 \mathrm{OR}$ & 1 & 1 & 3 & 2 & 2 & 2 & 1 & 1 & 1 & 2 & 2 & 4 & 2 & 2 & 2 & 2 & 2 & 2 \\
\hline $2 \mathrm{SR}$ & 2.5 & 1.5 & 1 & 1 & 1 & 2.5 & 1 & 1 & 2.5 & 1.5 & 1 & 1 & 1.5 & 2 & 2 & 2 & 1 & 1 \\
\hline $3 \mathrm{OR}$ & 1 & 2 & 4 & 1 & 3 & 3 & 2 & 2 & 1 & 2 & 2 & 4 & 2 & 2 & 3 & 2 & 4 & 2 \\
\hline 3SR & 2.5 & 1 & 2 & 1 & 2 & 2.5 & 1 & 2 & 3 & 2 & 1 & 1.5 & 1 & 1.5 & 1 & 1 & 1.5 & 2 \\
\hline $4 \mathrm{OR}$ & 1 & 2 & 4 & 1 & 3 & 2 & 2 & 2 & 1 & 1 & 1 & 4 & 2 & 2 & 2 & 2 & 3 & 3 \\
\hline 4SR & 1.5 & 2 & 2.5 & 1 & 2. & 1 & 1.5 & 1 & 1.5 & 1.5 & 1 & 1.5 & 1 & 1.5 & 1 & 1 & 1 & 1.5 \\
\hline $5 \mathrm{OR}$ & 2 & 2 & 2 & 2 & 3 & 2 & 2 & 2 & 1 & 2 & 2 & 4 & 3 & 2 & 2 & 2 & 1 & 3 \\
\hline 5SR & 2.5 & 1.5 & 1 & 1 & 1.5 & 1 & 1.5 & 1 & 2 & 2.5 & 1 & 1 & 1 & 2 & 1 & 1 & 2 & 1 \\
\hline $6 \mathrm{OR}$ & 2 & 1 & 3 & 3 & 3 & 2 & 3 & 2 & 2 & 2 & 2 & 3 & 3 & 2 & 2 & 3 & 1 & 2 \\
\hline 6SR & 1.5 & 1 & 1 & 1 & 1 & 1.5 & 2 & 1 & 1 & 1.5 & 2.5 & 1 & 1 & 1.5 & 1.5 & 1.5 & 1.5 & 2 \\
\hline 7OR & 2 & 1 & 2 & 2 & 3 & 2 & 1 & 3 & 2 & 2 & 2 & 3 & 3 & 2 & 2 & 2 & 1 & 3 \\
\hline 7SR & 2 & 1.5 & 1.5 & 1.5 & 2.5 & 1.5 & 1 & 1.5 & 3.5 & 1 & 1.5 & 1.5 & 1 & 1.5 & 1.5 & 1.5 & 1 & 1.5 \\
\hline $8 \mathrm{OR}$ & 2 & 2 & 2 & 2 & 3 & 2 & 3 & 2 & 2 & 2 & 2 & 3 & 3 & 2 & 2 & 2 & 1 & 3 \\
\hline 8SR & 1.5 & 2 & 1.5 & 1 & 1 & 2.5 & 1 & 2 & 2 & 1.5 & 2.5 & 1 & 1 & 2.5 & 1 & 3 & 2.5 & 2 \\
\hline 9OR & 2 & 1 & 2 & 1 & 3 & 2 & 1 & 2 & 2 & 2 & 2 & 3 & 3 & 2 & 2 & 2 & 1 & 2 \\
\hline 9SR & 2.5 & 3 & 1 & 3 & 2.5 & 3.5 & 1 & 2.5 & 4 & 3 & 1 & 1 & 1 & 2 & 1 & 1 & 1 & 2.5 \\
\hline $10 \mathrm{OR}$ & 4 & 2 & 2 & 3 & 3 & 3 & 2 & 2 & 4 & 2 & 2 & 3 & 2 & 2 & 1 & 1 & 4 & 2 \\
\hline $10 \mathrm{SR}$ & 2.5 & 2 & 2 & 1.5 & 1 & 1 & 2.5 & 1.5 & 2 & 2 & 1.5 & 1 & 1 & 1.5 & 1 & 1 & 1 & 1 \\
\hline $11 \mathrm{OR}$ & 4 & 2 & 2 & 3 & 3 & 2 & 2 & 2 & 4 & 2 & 2 & 4 & 2 & 2 & 2 & 2 & 2 & 2 \\
\hline $11 \mathrm{SR}$ & 4 & 3.5 & 3 & 2.5 & 2 & 1.5 & 2 & 1.5 & 2 & 2.5 & 1.5 & 2 & 2.5 & 2.5 & 3 & 2 & 1.5 & 1.5 \\
\hline $12 \mathrm{OR}$ & 4 & 1 & 2 & 3 & 3 & 3 & 2 & 2 & 4 & 2 & 3 & 4 & 2 & 2 & 2 & 2 & 2 & 3 \\
\hline $12 \mathrm{SR}$ & 3 & 2 & 3.5 & 3.5 & 1 & 2 & 2 & 2 & 3 & 1.5 & 1 & 2 & 1 & 2 & 2 & 1 & 1.5 & 1.5 \\
\hline 13OR & 1 & 1 & 4 & 2 & 2 & 2 & 4 & 1 & 1 & 1 & 2 & 4 & 2 & 2 & 2 & 2 & 3 & 2 \\
\hline 13SR & 1.5 & 1.5 & 1 & 1 & 1.5 & 2 & 1 & 1 & 1 & 1 & 1 & 1 & 1 & 1 & 1 & 1.5 & 1.5 & 1 \\
\hline $14 \mathrm{OR}$ & 1 & 1 & 3 & 1 & 1 & 1 & 1 & 1 & 1 & 1 & 1 & 4 & 3 & 2 & 1 & 1 & 2 & 1 \\
\hline 14SR & 1 & 1.5 & 2 & 1.5 & 1.5 & 1 & 1 & 1 & 1 & 1.5 & 1 & 1 & 1 & 1.5 & 1 & 1 & 2 & 1 \\
\hline $15 \mathrm{OR}$ & 1 & 1 & 2 & 1 & 2 & 2 & 1 & 1 & 1 & 2 & 1 & 4 & 2 & 2 & 2 & 1 & 2 & 2 \\
\hline $15 \mathrm{SR}$ & 1 & 1.5 & 1 & 1 & 1 & 1 & 1 & 1 & 1 & 1.5 & 1 & 1 & 1 & 1.5 & 1 & 1 & 1.5 & 1 \\
\hline $16 \mathrm{OR}$ & 1 & 1 & 2 & 2 & 3 & 1 & 1 & 2 & 1 & 2 & 1 & 4 & 2 & 2 & 2 & 1 & 2 & 3 \\
\hline 16SR & 2.5 & 2.5 & 2 & 1 & 1.5 & 1.5 & 1 & 1.5 & 2 & 2 & 1 & 2 & 1 & 1.5 & 1 & 1.5 & 2 & 2 \\
\hline $17 \mathrm{OR}$ & 4 & 1 & 2 & 1 & 3 & 2 & 3 & 3 & 4 & 2 & 2 & 3 & 2 & 1 & 2 & 2 & 4 & 3 \\
\hline $17 \mathrm{SR}$ & 2 & 1 & 1 & 1 & 1 & 4 & 1.5 & 1 & 2 & 1 & 1 & 1 & 1 & 1.5 & 1.5 & 1 & 1 & 3 \\
\hline $18 \mathrm{OR}$ & 3 & 1 & 2 & 1 & 3 & 2 & 2 & 3 & 4 & 2 & 2 & 4 & 2 & 1 & 2 & 2 & 3 & 3 \\
\hline $18 \mathrm{SR}$ & 1.5 & 1.5 & 1 & 1 & 1.5 & 4 & 1 & 1 & 3.5 & 1.5 & 1.5 & 1 & 1 & 1 & 1 & 1 & 1 & 2.5 \\
\hline $19 \mathrm{OR}$ & 3 & 1 & 2 & 1 & 3 & 2 & 3 & 3 & 4 & 2 & 2 & 3 & 2 & 2 & 2 & 2 & 4 & 2 \\
\hline 19SR & 1.5 & 1.5 & 1 & 1 & 1 & 2.5 & 1 & 1 & 1 & 1.5 & 1 & 1 & 1 & 1 & 1.5 & 1 & 1 & 1 \\
\hline $20 \mathrm{OR}$ & 2 & 1 & 2 & 3 & 3 & 2 & 3 & 2 & 4 & 2 & 2 & 2 & 1 & 1 & 1 & 2 & 2 & 1 \\
\hline 20SR & 1 & 1.5 & 1 & 1.5 & 2 & 1.5 & 1 & 1 & 1.5 & 1 & 1 & 1 & 1 & 1 & 1 & 1 & 1 & 2 \\
\hline
\end{tabular}

Table 3. Mann-Whitney test values for comparison between groups

\begin{tabular}{|c|c|c|c|c|c|}
\hline & \multicolumn{2}{|c|}{ Initial } & \multicolumn{2}{|c|}{ Final } & \multirow{2}{*}{$\begin{array}{c}\text { Retention } \\
\text { IG }\end{array}$} \\
\hline & IG & GWI & IG & GWI & \\
\hline Self-management to time & .76 & .001 & .39 & .06 & .07 \\
\hline Self-organization/problem solving & .004 & .004 & .59 & .72 & .06 \\
\hline Self-restraint & .72 & .006 & .02 & .02 & .001 \\
\hline Self-motivation & .66 & .008 & .96 & .20 & .20 \\
\hline Self-regulation of emotion & .03 & .003 & .14 & .04 & .03 \\
\hline Total & .02 & .00 & .13 & .009 & .001 \\
\hline
\end{tabular}

$p<.05$ Legend: $\mathrm{IG}=$ Intervention group; GWI= Group without intervention

between the domains, in both versions, points out the need for attention for some, with values below acceptable $(<.30)$, although the remaining ones are moderate, indicating the relation but not overlapping of the contents. There is a higher correlation between the total and the domains in the self-report, with three domains reaching values greater than .72 and therefore considered as strong, and moderate in the correlation of the remaining two domains with the total scale [31]. The correlations between the domains and the total of the scale pointed to the construct validity that, however, lacks more studies.

The answers of the caregivers and the self-report tend to moderate correlations [30], varying between .33 in self-regulation of emotion and .70 in self-restraint. The intervention group tends to have lower values, possibly explained by the higher functional level of these participants, and the lower results of self-organization domain can be 
Table 4. Descriptive Statistics and Wilcoxon test results in three moments of evaluation: Initial Assessment (IA), Final Assessment (FA) and Retention Assessment (RA)

\begin{tabular}{|c|c|c|c|c|c|c|c|c|c|c|}
\hline \multirow[t]{2}{*}{ SR } & \multicolumn{2}{|c|}{ IA } & \multicolumn{2}{|c|}{ FA } & \multicolumn{2}{|c|}{ RA } & \multicolumn{2}{|c|}{ IA vs. FA } & \multicolumn{2}{|c|}{ FA vs. RA } \\
\hline & IG & GWI & IG & GWI & IG & GWI & IG & GWI & IG & GWI \\
\hline SM & $6.7 \pm 1.82$ & $5.56 \pm-1.1$ & $5.67 \pm 2.29$ & $5.56 \pm 1.88$ & $5.0 \pm 1.12$ & - & .17 & 1 & .28 & - \\
\hline SO & $6.1 \pm 1.24$ & $6.17 \pm 1.32$ & $6.56 \pm 2.01$ & $7.11 \pm 1.76$ & $5.78 \pm 1.4$ & - & .51 & .11 & .17 & - \\
\hline SR & $9.2 \pm-1.9$ & $6.33 \pm-1.4$ & $6.33 \pm 2.83$ & $5.67 \pm 1.66$ & $4.89 \pm .60$ & - & .05 & .31 & .08 & - \\
\hline SM & $5.3 \pm .94$ & $5.06 \pm 1.01$ & $5.78 \pm 1.99$ & $4.89 \pm 0.93$ & $5.22 \pm .97$ & - & .51 & .58 & .28 & - \\
\hline SRE & $6.0 \pm 2.57$ & $4.83 \pm 1.44$ & $6.44 \pm 2.88$ & $5.22 \pm 1.79$ & $5.67 \pm 1.8$ & - & .29 & .59 & .31 & - \\
\hline $\mathrm{T}$ & $33.4 \pm 6.1$ & $27.9 \pm 4.05$ & $30.8 . \pm 6.7$ & $28.44 \pm 5.4$ & $26.6 \pm 3.4$ & - & .26 & .86 & .03 & - \\
\hline \multicolumn{11}{|c|}{ Other report } \\
\hline SM & $7.67 \pm 3.5$ & $9.44 \pm 3.09$ & $6.89 \pm 2.76$ & $7.67 \pm 2.55$ & $7.33 \pm 2.7$ & $8.2 \pm 2.7$ & .38 & .02 & .92 & .06 \\
\hline $\mathrm{SO}$ & $8.56 \pm 1.7$ & $9.0 \pm 2.69$ & $7.0 \pm 2.45$ & $7.44 \pm 1.42$ & $7.78 \pm 2.4$ & $8.0 \pm 1.4$ & .06 & .10 & .20 & .10 \\
\hline SR & $9.89 \pm 2.9$ & $8.89 \pm 2.09$ & $8.33 \pm 1.41$ & $7.56 \pm 1.13$ & $8.78 \pm 2.9$ & $7.4 \pm 0.7$ & .14 & .07 & .68 & .66 \\
\hline SM & $6.11 \pm 2.3$ & $8.11 \pm 3.33$ & $6.56 \pm 3.91$ & $6.67 \pm 3.00$ & $6.89 \pm 2.9$ & $6.8 \pm 2.8$ & .68 & .09 & .67 & .56 \\
\hline SRE & $9.78 \pm 3.6$ & $8.56 \pm 2.51$ & $8.33 \pm 2.83$ & $7.22 \pm 1.79$ & $8.11 \pm 2.1$ & $7.8 \pm 1.9$ & .20 & .09 & .75 & .06 \\
\hline $\mathrm{T}$ & $42.0 \pm 7.8$ & $44 \pm 11.09$ & $37.1 \pm 8.52$ & $36.56 \pm 5.2$ & $38.4 \pm 7.2$ & $38.2 \pm 6.4$ & .09 & .03 & 1 & .05 \\
\hline
\end{tabular}

SR: self-report; OR: other report; SM: Self-management to time; SO: Self-organization/problem solving; SR: Self-restraint; SM: Self-motivation; SRE: Self-regulation of emotion; IG: Intervention group; GWI: Group without intervention

due to institution organization where tasks are mostly organized and guided by proxies. Brown and Brown [37] recall that high correlation coefficients are not required among respondents because of the diversity of views on the same situation, which is why, despite the lack of a high "agreement" score, the correlations seem acceptable [30].

In general, scores obtained in the first evaluation moment, indicate difficulties in the executive functioning of the participants, with special emphasis on their recognition [2], which may be dependent on limitations in: attention ability vs. distractibility [19,20], memory $[19,26]$, intellectual functioning [16] or in establishment of abstract relationships between items [27]. The participants report difficulties in self-restraint and in self-organization, and caregivers point out selfrestraint and self-regulation of emotion, seeming to meet other studies $[3,10,12,21]$.

In the comparative study between both groups, there were significant differences, particularly in the initial evaluation, with more positive responses by the participants. In report-of-others were reported higher mean values, indicators of more executive limitation. This difference can be explained either by the self-valuing self-perception of the adult with ID [30] or by the comparison not with the typical peers but with the peers with whom they cohabit daily in the institution [35].

In this way, limitation on the self-management to time domain seem to point out a tendency, greater in the group without intervention and according to report-of-others, to the procrastination or lack of initiative for tasks accomplishment, needing constant support and encouragement from proxies [12,22]. All these difficulties associated with memory limitations $[19,26]$ and in the planning and anticipation of the response [15], results in lower productivity indexes requiring more time for the activities [22] with a less precise performance [6]. This difference between groups based on the caregiver's opinion can be explained by the greater autonomy and intellectual capacity level of some members of the group without intervention, who assume tasks of greater responsibility when compared with other participants. It is interesting to note that the participants with ID presents more positive responses and more competent indicators than their caregivers who tend to point out greater executive difficulties by clients with whom they work.

The self-organization/problem solving domain items [4] involves the ability and mastery of the logical sequence [38] inherent in the resolution and performance steps in activities, playing with cognitive speed and accuracy in information processing [6] with repercussions on learning ability [5] and problem solving [23-25]. Participants with ID appear to have, as before, a more positive view of their competencies, despite their expressed difficulties. It can be related with institutionalization and with the fact that tasks and activities proposed are adapted to meet their characteristics, and these difficulties are imperceptible this.

The self-restraint domain [4] involves the impulsiveness and ability to regulate behaviour and level of tolerance to frustration, and we observe limitations in all participants: i.e.: tendency for noninhibitory control $[3,12,21]$. This combined with the difficulties of the other domains already presented [4], have impact in the quality of performance in daily activities $[7,22]$ and with the tendency for greater mismatches [4]. These difficulties are evident in many moments in the daily life of the individuals, being more common in situations involving stress or contradictions to their ideas and wishes.

The domain of self-motivation [4] focuses on goal-oriented competencies [13,15,26,38], implying consistency of effort and commitment [12,22] and admitting errors [3], without the need for supervision and, like others, participants seems to have difficulties [22]. Finally, the domain of self-regulation of emotion implies the ability to analyse and adapt emotions and behaviours [3] with repercussions in the most varied contexts [6,7]. This whole set of characteristics will influence the performance of the innumerable activities of daily living [8], both in the scope of work precision and speed [6,22], and in sociobehavioural adjustment [22].

Comparing the various moments of evaluation to perceive the contribution that a psychomotor intervention can have in executive functioning stimulation, which is intended to be transferred to daily life, it is observed that the mean values in the final assessment seem to decrease in both groups, in both versions, pointing out to improvements in the executive functioning after the intervention. This decrease seems to indicate the potential contribution of an intervention of this nature, despite its reduced duration, which may explain the existence of significant differences in the self-restraint in the intervention group. This situation can result from greater behavioural awareness, but also from the specific work to promote aspects related to all domains, meeting the principles of psychomotor intervention [34] and interventions directed to executive functioning [3], which aim to develop skills that facilitate the adaptation of the individual in the day to day $[3,34]$. It should be noted, however, that when comparing the results one month later 
without intervention, the mean values tend to increase, which refers to the need for continuous stimulation of this type of competences, in an institutional and domiciliary context, despite the significant difference found in the total of the scale, in this last moment of evaluation.

Unexpectedly, the analysis of report-of-others did not reflect any significant differences in the intervention group, despite the decrease in mean values after the psychomotor intervention, showing once again a slight increase of these values at the time of the retention evaluation. The group without intervention obtained significant differences in the self-management to time, with evident improvements in the second evaluation moment, which could have been the result of other supports that they enjoyed or of their own capacities.

\section{Conclusion}

People with ID tend to exhibit difficulties in executive functioning that is translated into mismatches in daily life. According to the most recent paradigms, evaluation and identification of the individual needs and capacities should be done as soon as possible, for an adjusted supports provision for a life with more quality and participated [39]. One of these supports may be Psychomotor Rehabilitation [40] although, even with the recent increase research in this area [28], little is known about its impact in the scope of promoting executive functioning. The author also refers that there is still little evidence to select a specific type of services and interventions for people with ID.

Based on the results, it seems possible to predict that a psychomotor intervention centred on executive functioning may have a positive impact on the improvement of some of these competences - the ability to control impulsive behaviours, manage temporal situations, organize and solve problems, emotional self-regulation in the face of various situations that arise in their daily lives. Moreover, it can also help in the apparent better recognition of their own limitations and difficulties, through behaviour awareness (adequate vs. inadequate) and work in finding individual strategies for better adjustment to the context, suggesting an in-depth analysis. Despite the short duration of the intervention, the few evidences found indicate the potential of psychomotor intervention as one of the supports to adults with ID $[28,40]$.

According to the most recent assessments in the area, the active role of the participant with ID throughout the entire intervention process is highlighted, as well as the attention to collect information by different respondents [35]: i.e., people with ID and a significant caregiver [33]. There was some discrepancy between participants with ID and their caregivers. It is necessary to consider that the response in self-report implies the understanding of what is questioned (verbal language), the memory to remember the typical behaviours that it usually exhibits different situations as well as the response options, and the implementation of the response (verbal or motor).

This research presents some limitations such as the reduced sample, the lack of control of possible moderating variables (e.g.: level of IQ, adaptive profile, medication, complementary therapeutic interventions) and the short duration of the psychomotor intervention. It is suggested to continue researching the executive functioning of adults with ID, with representative samples that allow the establishment of an executive profile, the identification of its predictors, or longitudinal studies focused on the interventions' effectiveness of executive functions. It can also be referred the need for valid instruments for the assessment of executive functions.

\section{Acknowledgement}

\section{Authorship and Contribution ship}

All authors contribute to the conception, design and writing of the study, as well the instruments application and data acquisition. All authors participated on analysis and interpretation of data, with critical important reviews and gave their final approval of the version to publish, agreeing to act as a guarantor of the work.

\section{Competing Interests}

The author(s) declare that they have no competing interests.

\section{References}

1. Schalock R, Luckasson R, Bradley V, Buntinx W, Lachapelle Y, et al. (2012) User's Guide: Intellectual Disability Definition. AAIDD

2. Danielsson H, Henry L, Ronnberg J, Nilsson LG (2010) Executive functions in individuals with intellectual disability. Res Dev Disabil 31: 1299-1304 [Crossref]

3. Diamond A (2013) Executive Functions. Annual review of psychology. Annu Rev Psychol 64: 135-168 [Crossref]

4. Barkley R (2011) Barkley Deficits in Executive Functioning Scale (BDEFS). New York: The Guilford Press.

5. Borella E, Carretti B, Pelegrina S (2010) The specific role of inhibition on reading comprehension in good and poor comprehenders. J Learn Disabil. 43: 541-552. [Crossref]

6. Bailey CE (2007) Cognitive Accuracy and Intelligent Executive Function in Brain and in Business. Ann N Y Acad Sci 1118: 122-141. [Crossref]

7. Denson T, Pedersen W, Friese M, Hahm A, Roberts L (2011) Understanding impulsive aggression: angry rumination and reduced self-control capacity are mechanisms underlying the provocation-aggression relatioship. Pers Soc Psychol Bull 37: 850-862. [Crossref]

8. Brown T, Landgraf JM (2010) Improvements in Executive Function Correlate with Enhanced Performance and Functioning and Health-Related Quality of Life: Evidence from 2Large, Double-blind, Randomized, Placebo-Controlled trials in ADHD. Postgrad Med 122: 42-51. [Crossref]

9. Jurado B, Rosselli M (2007) The elusive nature of executive functions: a review of our current understanding. Neuropsychol Rev 17: 213-233. [Crossref]

10. Eslinger P, Flaherty-Craig C, Benton A (2004) Developmental outcomes after early prefrontal cortex damage. Brain Cogn 55: 84-103. [Crossref]

11. Best J, Miller PH (2010) A developmental perspective on executive function. Child Dev 81: 1641-1660. [Crossref]

12. Hauser-Cram P, Woodman A, Heyman M (2014) Early Mastery Motivation as a Predictor of Executive Function in Young Adults with Developmental Disabilities. Am J Intellect Dev Disabil 119: 536-551 [Crossref]

13. Hughes C (2011) Changes and challenges in 20 years of research into the development of executive functions. Infant and Child Development 20: 251-271.

14. Willcutt E, Doyle A, Nigg J, Faraone S, Pennington BF (2005) Validity of the executive function theory of attention-deficit/hyperactivity disorder: a meta-analytic review. Biol Psychiatry. 57: 1336-1346. [Crossref]

15. Skoff B (2004) Executive Functions in Developmental Disabilities. Insights on Learning Disabilities 15: 4-10.

16. Friedman NP, Miyake A, Corley RP, Young SE, Defries JC, et al. (2006) Not all executive functions are related to intelligence. Psychol Sci 17: 172-179. [Crossref]

17. Maehler C, Schuchardt K (2009) Working memory functioning in children with learning disabilities: does intelligence make a difference? J Intellect Disabil Res 53: 3-10 [Crossref]

18. Willner P, Bailey R, Parry R, Dymond S (2010) Evaluation of executive functioning in people with intellectual disabilities. J Intellect Disabil Res 54: 366-379. [Crossref]

19. Kirk H, Gray K, Riby D, Cornish K (2015) Cognitive training as a resolution for early executive function difficulties in children with intellectual disabilities. Res Dev Disabil 38: 145-160. [Crossref] 
20. Steele A, Karmiloff-Smith A, Cornish K, Scerif G (2012) The Multiple Subfunctions of attention: Differential Developmental Gateways to literacy and Numeracy. Child Dev 83: 2028-2041. [Crossref]

21. Levitas A, Dykens E, Finucane B, Kates W (2007) Behavioural Phenotype of Genetic Disorders. Em: Fletcher R, Loschen E, Stavrakaki C, and First M (ed), Diagnostic Manual- Intellectual Disability: A Textbook of Diagnosis of Mental Disorders in Persons with Intellectual Disability (33-62). Kingston, New York: National Association for the Dually Diagnosed.

22. Santos S, Morato P (2012) Adaptive Behaviour on the Portuguese Curricula: A Comparison between Children and Adolescents with and without Intellectual Disability. Creative Education 5: 501-509

23. Numminen H, Lehto J, Ruoppila I (2001) Tower of Hanoi and working memory in adult persons with intellectual disability. Research in Developmental Disabilities 22 373-387.

24. Numminen H, Service E, Ruoppila I (2002) Working memory, intelligence and knowledge base in adult persons with intellectual disability. Research in Developmental Disabilities 23: 105-118.

25. Levén A, Lyxell B, Andersson J, Danielsson H, Rönnberg J (2008) Prospective memory, working memory, retrospective memory and self-rated memory performance in individuals with intellectual disability. SJDR 10: 147-165.

26. Alloway T (2010) Working memory and executive function profiles of individuals with borderline intellectual functioning. J Intellect Disabil Res 54: 448-456. [Crossref]

27. Sgaramella T, Carrieri L, Barone C (2012) A screening battery for the assessment of executive functioning in young and adult individuals with intellectual disability. International Journal on Disability and Human Development 11: 31-37

28. Santos S (2017) Psychomotor therapy and intellectual disability: from 0 to 100 . IJPN 3: 22-37.
29. Allee-Smith P, Winters R, Drake A, Joslin A (2013) Test Review. Journal of Psychoeducational Assessment 31: 80-83.

30. Andresen E (2000) Criteria for assessing the tools of disability outcomes research Archives of Physical Medicine and Rehabilitation 81: S15-S20.

31. Hartley S, MacLean W (2006) A review of the reliability and validity of Likert-type scales for people with intellectual disability. $J$ Intellect Disabil Res 50: 813-827. [Crossref]

32. Wynd C, Schmidt B, Schaefer M (2003) Two quantitative approaches for estimating content validity. West J Nurs Res 25: 508-518. [Crossref]

33. Balboni G, Coscarelli A, Giunti G, Schalock R (2013) The assessment of the quality of life of adults with intellectual disability: The use of self-report and report of others assessment strategies. Res Dev Disabil 34: 4248-4254. [Crossref]

34. Santos S (2014) Adaptive Behaviour on the Portuguese Curricula: A Comparison between Children and Adolescents with and without Intellectual Disability. Creative Education 5: 501-509.

35. Simoes C, Santos S (2016) Comparing the Quality of Life of adults with and without intellectual disability. JIDR 60: 378-388.

36. Straughen J, Caldwell C, Osypuk T, Helmkamp L, Misra D (2013) Direct and proxy recall of childhood socio-economic position and health. Paediatr Perinat Epidemiol 27: 294-302. [Crossref]

37. Brown I, Brown R (2003) Quality of life and disability: An approach for community practitioners. London, UK: Kingsley

38. Stirling J (2002) Introducing Neuropsychology. Nova Iorque: Psychology Press.

39. Brown I, Hatton C, Emerson E (2013) Quality of Life for Individuals with Intellectua Disabilities: Extending current practice. Intellect Dev Disabil 51: 316-332. [Crossref]

40. Ramos J, Sousa E, Estevens M, Duarte F, Santos S (2017) A acessibilidade na visão do psicomotricista em contexto institucional: CERCI Lisboa. A Psicomotricidade. (in press)

Copyright: (C2019 Rodrigues AR. This is an open-access article distributed under the terms of the Creative Commons Attribution License, which permits unrestricted use, distribution, and reproduction in any medium, provided the original author and source are credited. 